\title{
Vaping patterns, nicotine dependence and reasons for vaping among American Indian dual users of cigarettes and electronic cigarettes
}

Dorothy A. Rhoades ${ }^{1 *}$ (D) Ashley L. Comiford ${ }^{2}$, Justin D. Dvorak ${ }^{3}$ Kai Ding ${ }^{3}$, Michelle Hopkins ${ }^{3}$, Paul Spicer ${ }^{4}$, Theodore L. Wagener ${ }^{5}$ and Mark P. Doescher ${ }^{6}$

\begin{abstract}
Background: The American Cancer Society discourages the dual use of electronic cigarettes (ECS) and cigarettes because such use has not resulted in reduced exposures to the harmful effects of smoking. American Indian (Al) people have the highest prevalence of smoking and of EC use in the United States, but very little is known about dual EC and cigarette use in Al communities.
\end{abstract}

Methods: In 2016, 375 adult Al in Oklahoma who smoked cigarettes completed a survey about EC use (vaping). We describe vaping patterns, nicotine dependence, and reasons for EC use among the subset of 44 (12\%) current dual EC users. To differentiate habitual EC users from occasional or merely curious users, we defined dual use as using ECs on some days or every day in the past 30 days.

Results: About one-third of dual users vaped ten or more times daily. About two-thirds used a tank product. Eleven percent used ECs without nicotine and another 9\% were unsure of the nicotine content. A minority (40\%) enjoyed vaping more than smoking, and most (76\%) would smoke first on days they did both. Thirty-one percent vaped within 5 min of waking and another $24 \%$ within 30 min. Although the two-item heaviness of use index did not differ significantly between smoking and vaping, the ten-item Penn State Dependence Index (PSDI) suggested greater dependence on smoking than vaping (11.02 vs. 6.42 , respectively; $p<.0001)$. The most common reasons for vaping were to reduce smoking (79\%), enjoyment of flavors (78\%), and ability to vape where smoking is not allowed (73\%). Perceptions of less harm to others (69\%) or to self were the next most common (65\%). Fewer than half used ECs to reduce stress, for affordability, or because others used them.

Conclusions: Nearly 20\% of dual users used ECs either without nicotine or without knowing if the product contained nicotine. The PSDI indicated greater dependence on smoking than vaping. Reasons for vaping were nearly equal between smoking reduction and enjoying flavors. Understanding patterns of dual use will inform future efforts to address nicotine dependence for Al communities with high prevalence of smoking.

Keywords: Electronic cigarettes, Smoking, American Indian, Adult, Tobacco use

\footnotetext{
* Correspondence: Dorothy-Rhoades@ouhsc.edu

${ }^{1}$ Department of Medicine, University of Oklahoma Health Sciences Center, and Stephenson Cancer Center, 655 Research Parkway, Room 449, Oklahoma City, OK 73104, USA

Full list of author information is available at the end of the article
}

(c) The Author(s). 2019 Open Access This article is distributed under the terms of the Creative Commons Attribution 4.0 International License (http://creativecommons.org/licenses/by/4.0/), which permits unrestricted use, distribution, and reproduction in any medium, provided you give appropriate credit to the original author(s) and the source, provide a link to the Creative Commons license, and indicate if changes were made. The Creative Commons Public Domain Dedication waiver (http://creativecommons.org/publicdomain/zero/1.0/) applies to the data made available in this article, unless otherwise stated. 


\section{Introduction}

The prevalence of smoking in the U.S. is decreasing [1] and the prevalence of electronic cigarette (EC) use increasing [2]. Many individuals use ECs, or vape, in effort to reduce or quit smoking [3-5]. While complete substitution of ECs for cigarettes has been associated with smoking cessation [6,7], concomitant or "dual" use of ECs and cigarettes has not [8], and dual use is now the most common form of EC use [9]. Further, dual use has not been shown to reduce exposure to the harmful products of combustible cigarettes, including carcinogens [10-18]. The American Cancer Society, as a result, strongly discourages the dual use of EC and cigarettes [19]. Additionally, recent evidence suggests that frequent vaping itself carries increased risk of cardiovascular disease $[20,21]$, and newer generation EC devices can achieve nicotine levels comparable or exceeding those of conventional cigarettes [22], increasing the potential for adverse effects from nicotine.

The American Indian (AI) population in general has a very high smoking prevalence, particularly in the Plains states [23-26]. AI people also have the highest prevalence of EC use of any single-race group in the U.S. [27, 28]. However, use of EC by AI who smoke has been reported only rarely $[29,30]$, and the patterns and preferences of EC use among AI dual users, never. We now describe patterns, EC dependence, and preferences by focusing on the dual user subset, defined as people who smoked cigarettes and used ECs on some days or every day of the past 30 days. This common definition [31] minimizes the inclusion of people who merely experimented with ECs once or twice, and allows focus on persons with more habitual EC use.

\section{Methods}

The "Vaping among Smokers: A Cherokee Nation Cohort Study" was designed to provide estimates of the prevalence and patterns of EC use among adult AI smokers and has been described in detail elsewhere [30]. Briefly, in 2016 we recruited 375 adult AI men and women, who smoke, at a large Cherokee Nation Health Services outpatient facility in northeastern Oklahoma to participate in the study. Eligibility for services includes proof of AI or Alaska Native (AN) descent, such as a Certificate of Degree of Indian Blood (CDIB), from a federally recognized AI or Alaska Native tribe or community. Eligibility to participate in the cohort included being age 18 years or older, smoking at least 100 cigarettes in one's lifetime, smoking in the past 30 days, and answering "yes" to both "Are you American Indian?" and "Do you have a CDIB card?"

Participants completed a survey including patterns of smoking and EC use. The current cross-sectional descriptive analysis is limited to the subset of dual users as defined below.

\section{Measures}

All participants reported whether they ever used ECs, and if so, whether they used any in the past 30 days [30]. Among these, dual users were defined as using EC on some days or every day within the past 30 days. This definition of dual use reduces the chance of including persons whose vaping was limited to curiosity or brief experimentation [31].

\section{Vaping measures}

Dual users reported how many times per day they used an EC (categorized as: less than 5, 5-9, 10-14, $15-19,20-29$, or 30 or more), which type of product most often used (cigalike, tank, mods, other), whether their e-liquid contained nicotine (yes, no, don't know/not sure) and the nicotine content of their usual EC product $(0 \mathrm{mg}, 1-12 \mathrm{mg}, 13-17 \mathrm{mg}$, $18+\mathrm{mg}$, don't know/not sure). Dual users also reported whether they enjoyed vaping more than smoking, and whether they use EC vs a cigarette first on days they use both.

Vaping dependence and smoking dependence were separately assessed using the Heaviness of Vaping Index [32], Heaviness of Smoking Index [33] and the Penn State Dependence Index (PSDI) for vaping or smoking [32] as adapted slightly for this study (Appendix). The Heaviness of Vaping and Heaviness of Smoking indices are two-item measures of nicotine dependence for EC users and smokers, respectively. The PSDI for vaping and PSDI for smoking are 10-item indices to measure dependence on vaping or smoking, respectively. Cases with any missing component of the index were excluded from the scoring to reduce bias towards low dependence [32].

Participants indicated one or more reasons for using ECs, including to reduce cigarette smoking, liking the flavors, using when smoking is not allowed, less harmful to self than smoking, less harmful to others than smoking, reducing stress, better affordability, and/or other people important to them use ECs, or other (write in).

\section{Analysis}

Categorical data are represented by count (percent). Continuous data are represented using the mean (SD). Dependence scales were assessed for normality using the Shapiro-Wilk test and visual confirmation via quantilequantile plots, then compared between vaping and smoking using paired t-tests with complete case analysis. The Shapiro-Wilk test is a commonly-applied method to assess normality assumptions underlying parametric statistical procedures [34, 35]. All analyses were performed using SAS software v9.4 and R v3.5.1. 


\section{Results}

Of the 375 enrolled participants, 44 (12\%) were dual users, defined as using ECs on some or all of the past 30 days.

Table 1 shows that among dual users, about one-third vaped 10 or more times a day, and less than one-half vaped fewer than 5 times per day. "Cigalikes" were the least frequently used product and tank systems were the most frequently used product. While $80 \%$ indicated that their e-liquid contained nicotine, $11 \%$ used e-liquid without nicotine, and $9 \%$ were unsure or did not know if their e-liquid contained nicotine. The most frequently reported nicotine content was $12 \mathrm{mg}$ or less, but $14 \%$ did not know the nicotine concentration. More than half did not find vaping more enjoyable than smoking and most reported smoking before vaping on days they did both.

Vaping and smoking dependence item measures and scales are shown in Table 2. Although 76\% reported smoking before vaping as noted above, vaping or smoking within the first 5 min of waking was not infrequent

Table 1 Vaping patterns and preferences, American Indian EC dual users $(N=44)$

Frequency

Frequency of EC use per day

Less than 5 times per day

5-9 times per day

10 or more times per day

Type of EC product used most often

Cigalike

Tank

Mods

Other

E-liquid contains nicotine

Yes

No

Don't know/Not sure

Usual E-liquid nicotine content

$$
0 \mathrm{mg}
$$

1-12 mg

$13-17 \mathrm{mg}$

18 or more mg

Don't know/Not sure

Enjoy vaping more than smoking

Yes

$40 \%$

No

On vaping days, which is used first

Cigarette

EC

EC Electronic Cigarette for either habit (31\% and 24\%, respectively), and cumulatively, the frequency of vaping or smoking within $30 \mathrm{~min}$ of waking was the same (55\%). Individual measures show more dependence on smoking than vaping. Heaviness of vaping index and heaviness of smoking index did not differ significantly among the dual users $(p=0.22)$, but the mean PSDI dependence score for vaping was significantly lower than that for smoking $(6.4+/-4.8$ vs 11.0 $+/-5.0$, respectively; $p<.0001)$. Results were unchanged when median values of the PSDI were compared via the Wilcoxon signed-rank test (6 vs $11, p<.0001$ ).

Reasons for vaping are shown in Fig. 1. The top three most commonly endorsed reasons for vaping were to cut down on smoking, liking EC flavors, and being able to vape in places wherein smoking is not allowed. Perceiving less harm to others or to oneself compared with smoking were the next most frequent responses. Less than one-half endorsed using EC to reduce stress, reduce cost, or because other persons important to them used EC. Other reasons (write in) for EC use were endorsed by only two $(4.5 \%)$ participants.

\section{Discussion}

In this cohort of adult AI persons who smoke, the prevalence of dual use, defined as using EC on some or all of the past 30 days, was $12 \%$. This definition of dual use is similar to other longitudinal studies $[7,36]$ and helps to exclude recent experimenters or infrequent users [31]. Other studies vary widely in estimates of prevalence of dual use by smokers. In a 2014 study, nearly $52 \%$ of a cohort of smokers used ECs either daily or more than just a few days [7]. However, in a 2013 study, prevalence of EC use more than 50 times during lifetime was only $3.8 \%$ among smokers [37] and among current smokers in the Current Population Survey in 2014, regular EC use among smokers was 3.6\% [38]. Definitions of dual use may vary enough to limit our ability to directly compare prevalence estimates between different cohorts, and the rapid rise in EC use also limits comparison with older studies. Standardized definitions of dual use will be useful in future studies.

\section{Vaping patterns}

Vaping 10 or more times per day was reported by onethird of the dual users. Very few studies report on the frequency of vaping by dual users, and often use different measures [39]. Given the continued debate regarding utility of EC in smoking cessation [40] and evidence of no clear benefit of dual EC and cigarette use [17], frequency of vaping needs more exploration by this group of smokers. Again, standardization of measures of vaping frequency will help in comparing future studies.

First generation (cigalike) ECs were the least often used products and the second-generation "tank" 
Table 2 Vaping dependence and smoking dependence measures among adult Al dual EC and cigarette users $(N=44)$

\begin{tabular}{|c|c|c|c|c|c|c|}
\hline \multicolumn{2}{|l|}{ Vaping Dependence Measures } & $\%$ & \multicolumn{3}{|l|}{ Smoking Dependence Measures } & $\%$ \\
\hline \multicolumn{3}{|l|}{ Minutes after waking use first EC } & \multicolumn{4}{|c|}{ Minutes after waking use first cigarette } \\
\hline \multicolumn{2}{|l|}{5 or less } & $31 \%$ & \multicolumn{3}{|l|}{5 or less } & $24 \%$ \\
\hline \multicolumn{2}{|l|}{$6-30$} & $24 \%$ & \multicolumn{3}{|l|}{$6-30$} & $31 \%$ \\
\hline \multicolumn{2}{|l|}{$31-120$} & $24 \%$ & \multicolumn{3}{|l|}{$31-120$} & $38 \%$ \\
\hline \multicolumn{2}{|l|}{$121+$} & $21 \%$ & \multicolumn{3}{|l|}{$121+$} & $7 \%$ \\
\hline \multicolumn{3}{|l|}{ Nights per week wake to use EC } & \multicolumn{4}{|l|}{ Nights per week wake to smoke } \\
\hline \multicolumn{2}{|l|}{ Never/less than weekly } & $73 \%$ & \multicolumn{3}{|l|}{ Never/less than weekly } & $54 \%$ \\
\hline \multicolumn{2}{|l|}{1 to 2} & $12 \%$ & \multicolumn{3}{|l|}{1 to 2} & $23 \%$ \\
\hline \multicolumn{2}{|l|}{3 or more } & $15 \%$ & \multicolumn{3}{|l|}{3 or more } & $23 \%$ \\
\hline \multicolumn{3}{|c|}{ Continue using EC because hard to quit } & \multicolumn{4}{|c|}{ Continue to smoke because hard to quit } \\
\hline \multicolumn{2}{|l|}{ Yes } & $44 \%$ & \multicolumn{3}{|l|}{ Yes } & $80 \%$ \\
\hline \multicolumn{2}{|l|}{ No } & $56 \%$ & \multicolumn{3}{|l|}{ No } & $20 \%$ \\
\hline \multicolumn{3}{|c|}{ Ever have strong cravings to use EC } & \multicolumn{4}{|l|}{ Ever have strong cravings to smoke } \\
\hline \multicolumn{2}{|l|}{ Yes } & $33 \%$ & Yes & & & $84 \%$ \\
\hline No & & $67 \%$ & No & & & $16 \%$ \\
\hline How strong were urges to vape, & st week & & How strong were urges to smoke & ast week & & \\
\hline None & & $44 \%$ & None & & & $0 \%$ \\
\hline Slight & & $34 \%$ & Slight & & & $18 \%$ \\
\hline Moderate & & $10 \%$ & Moderate & & & $25 \%$ \\
\hline Very/extremely strong & & $22 \%$ & Very/extremely strong & & & $57 \%$ \\
\hline Hard to keep from using EC & & & Hard to keep from smoking & & & \\
\hline Yes & & $36 \%$ & Yes & & & $58 \%$ \\
\hline No & & $64 \%$ & No & & & $42 \%$ \\
\hline WHEN HAVE NOT USED [EC; toba & 7 for a while C & when you tries & stop [vaping; smoking] ... & & & \\
\hline Irritable because can't use EC & & & Irritable because can't smoke & & & \\
\hline Yes & & $32 \%$ & Yes & & & $73 \%$ \\
\hline No & & $68 \%$ & No & & & $27 \%$ \\
\hline Nervous because can't vape & & & Nervous because can't smoke & & & \\
\hline Yes & & $32 \%$ & Yes & & & $66 \%$ \\
\hline No & & $68 \%$ & No & & & $34 \%$ \\
\hline Composite Dependence Scores & & & & & & $p$-value* \\
\hline Heaviness of Vaping Index [32] & Mean (SD) & $2.07(1.76)$ & Heaviness of Smoking Index [33] & Mean (SD) & $2.36(1.66)$ & .2155 \\
\hline PSDI-EC [32] & Mean (SD) & $6.42(4.84)$ & PSDI-smoking [32] & Mean (SD) & $11.02(5.00)$ & $<.0001$ \\
\hline
\end{tabular}

EC Electronic Cigarette

PSDI Penn State Dependence Index

Missing = 10 for Heaviness of Vaping Index, 12 for PSDI-EC, 2 for Heaviness of Smoking Index, and 3 for PSDI-smoking

*Paired t-test on the differences between the vaping dependence scores and smoking dependence scores

products the most often used. Second- and third-generation products allow users to customize their product, unlike the first generation cigalikes [41], in ways that likely improve the nicotine delivery $[22,42]$.

\section{Nicotine content of vaping products among dual users} While the majority of participants used ECs that contained nicotine, nearly $20 \%$ either did not or were unsure if they did. In another study, of 399 adult EC users who were current smokers in 2015, 337 (80.7\%) used EC containing nicotine, with $19 \%$ not [43]. While many smokers who also use ECs do so to reduce smoking, several EC users did not know the nicotine content of their EC product, or even if the product contained nicotine. If ECs are to replace, rather than supplement combustible cigarettes, nicotine content may be an important factor. 


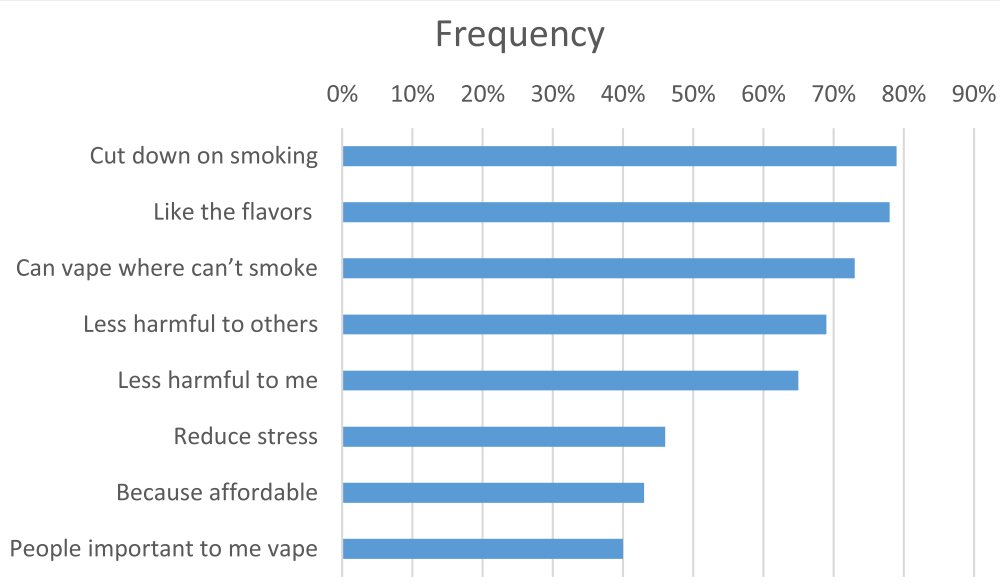

Fig. 1 Reasons for vaping among American Indian dual EC and cigarette users

\section{Measures of EC dependence}

Measures of EC dependence were relatively low compared to measures of cigarette dependence among these dual users, similar to findings in other studies [32, 39, $44,45]$. In our study, all participants were current smokers at baseline, so EC dependence among these dual users are not directly comparable to studies of exclusive EC uses. In addition, a relatively higher proportion of dual EC users had missing data for the vaping dependence scales, but the effect of this potential bias is unclear. Smoking dependence questions preceded vaping dependence questions in our survey and the similarity in questions and format may have confused participants. Whether ECs had reduced these respondents' dependence on cigarettes could not be assessed in this study.

\section{Reasons for vaping}

Flavoring was the most often endorsed reason for vaping. The impact of flavoring has never been reported for AI who smoke and use ECs. The role of flavoring in use of EC products is of increasing interest. A recent study found that flavors influenced nicotine exposure through flavor liking, but also contributed to heart rate acceleration, and nicotine titration [46]. In the US, sales of flavored EC products have greatly increased, including in Oklahoma [47]. In one study, adult smokers' interest in flavored EC was modest, but among the smokers who also use ECs, EC use was most affected by flavor [48]. In contrast, flavoring was only infrequently (14.7\%) cited as a reason for $\mathrm{EC}$ use by current smokers in a national survey [5].

Other than using EC to stop smoking, the convenience of vaping in places where smoking was not allowed was another leading reason for vaping. More than half cited their perception of EC being less harmful to others, and stress, affordability, or others' vaping were among the least common. Reasons for dual use of EC among smokers usually include desire to quit smoking $[49,50]$, and perceptions of less harm than cigarettes [49, 51], but other factors are less frequently assessed.

\section{Limitations}

A small, convenience and clinic-based sample limits our study. In addition, patterns of tobacco use vary across AI communities in the US, and findings from this study may not reflect use in other regions. Nonetheless, this pilot study took place in a region with high prevalence of tobacco use and provides a unique snapshot of AI dual users and their vaping habits. Larger, population based studies will greatly help to elucidate regional differences in the effects of ECs upon the smoking habits of AI people. As EC technology continues to evolve rapidly, the types of EC products used in 2016 may not reflect currently used EC products. Follow up studies are needed to assess changes in use over time.

\section{Appendix}

The Penn State Electronic Cigarette Dependence Index [32] as adapted for this study.

1. How many times per day do you usually use your electronic cigarette? (Scoring: 0-4 times/day $=0,5-$ $9=1,10-14=2,15-19=3,20-29=4,30+=5$ ),

2. How soon after you wake up do you first use your e-cig or vape? (Scoring: $0-5 \mathrm{~min}=5,6-15=4,16-$ $30=3,31-60=2,61-120=1,121+=0)$,

3. Do you sometimes awaken at night to vape or use your e-cig? (Yes = 1, No = 0),

4. How many nights per week do you typically wake up to vape or use your e-cig? I never wake up at night to vape, less than one night per week, 1 night per week, 2 nights per week, 3 nights per week, 4 or more nights per week. (Scoring 0-1 nights $=0,2-3$ nights $=1,4+$ nights $=2$ ) 
5. Do you vape or use an e-cig now because it is really hard to quit? (Yes $=1, \mathrm{No}=0)$

6. Do you ever have strong cravings to use an e-cig or vape? $($ Yes $=1, \mathrm{No}=0)$

7. Over the past week, how strong have the urges to vape or use an e-cig been? None, slight, moderate, strong, very strong, extremely strong. (Scoring: None/slight $=0$, Moderate/Strong $=1$, Very Strong/ Extremely strong $=2$ )

8. Is it hard to keep from using an e-cig or vaping in places where you are not supposed to, such as restaurants, hospital/clinics, or other public areas? $($ Yes $=1, \mathrm{No}=0)$

9. When you haven't used an e-cig or vaped for a while or when you tried to stop ... Did you feel more irritable because you couldn't vape or use an e-cig? $($ Yes $=1, \mathrm{No}=0)$

10. When you haven't used an e-cig or vaped for a while or when you tried to stop ... Did you feel nervous, restless, or anxious because you couldn't vape or use an e-cig? (Yes $=1, \mathrm{No}=0)$

\section{Abbreviations}

Al: American Indian; AN: Alaska Native; CDIB: Certificate of Degree of American Indian or Alaska Native Blood; EC: electronic cigarette; US: United States

\section{Acknowledgements}

The authors acknowledge Ms. Gloria Tallbull, research staff at the University of Oklahoma, and the staff at Cherokee Nation Health Services for their assistance in carrying out this project.

\section{Authors' contributions}

DAR co-designed the study, contributed to analysis and interpretation of the data, drafted and revised the manuscript. AC co-designed the study and was a major contributor to the writing of the manuscript. JD and KD conducted the majority of analyses, were major contributors to the interpretation of the data, and contributed to the writing of the manuscript. $\mathrm{MH}$ collected the data and contributed to the design of the study. PS acquired funding support and contributed to the writing of the manuscript. TW contributed to the design of the study, interpretation of the data, and writing of the manuscript. MD was a major contributor to the design of the study, interpretation of the data, and writing of the manuscript. All authors read and approved the final manuscript.

\section{Funding}

Grants from the National Cancer Institute of the National Institutes of Health (P20CA202921 to University of Oklahoma, and 5P20CA202923 to Cherokee Nation) supported this study. The funding body had no role in the design of the study and collection, analysis, interpretation of data, or writing the manuscript. Content is solely the responsibility of the authors and does not represent the official views of the National Institutes of Health or of Cherokee Nation.

\section{Availability of data and materials}

The data that support the findings are available from Cherokee Nation, but restrictions apply to the availability of these data. These data were used under agreement for the current study, and are not publicly available. Data are, however, available from the authors but only with explicit permission of Cherokee Nation.

\section{Ethics approval and consent to participate}

The Cherokee Nation Institutional Review Board and the University of Oklahoma Health Sciences Center Institutional Review Board (IRB case number 5970) approved this study. All participants provided written informed consent.

\section{Consent for publication}

Not applicable.

\section{Competing interests}

The authors declare that they have no competing interests.

\section{Author details}

${ }^{1}$ Department of Medicine, University of Oklahoma Health Sciences Center, and Stephenson Cancer Center, 655 Research Parkway, Room 449, Oklahoma City, OK 73104, USA. Epidemiology, Cherokee Nation, Tahlequah, OK, USA. ${ }^{3}$ College of Public Health, University of Oklahoma Health Sciences Center, Oklahoma City, OK, USA. ${ }^{4}$ Center for Applied Social Research, University of Oklahoma, Norman, OK, USA. ${ }^{5}$ Oklahoma Tobacco Research Center, Stephenson Cancer Center, University of Oklahoma Health Sciences Center, Oklahoma City, OK, USA. 'Department of Family Medicine, University of Oklahoma Health Sciences Center, and Stephenson Cancer Center, Oklahoma City, OK, USA.

Received: 13 May 2019 Accepted: 21 August 2019

Published online: 02 September 2019

\section{References}

1. Jamal A, King BA, Neff LJ, Whitmill J, Babb SD, Graffunder CM. Current cigarette smoking among adults - United States, 2005-2015. MMWR Morb Mortal Wkly Rep. 2016;65(44):1205-1211. Epub 2016/11/11. doi: https://doi. org/10.15585/mmwr.mm6544a2. PubMed PMID: 27832052.

2. King BA, Patel R, Nguyen KH, Dube SR. Trends in awareness and use of electronic cigarettes among US adults, 2010-2013. Nicotine Tob Res. 2015; 17(2):219-227. Epub 2014/09/23. doi: https://doi.org/10.1093/ntr/ntu191. PubMed PMID: 25239961; PMCID: PMC4512831.

3. McMillen RC, Gottlieb MA, Shaefer RM, Winickoff JP, Klein JD. Trends in electronic cigarette use among U.S. adults: use is increasing in both smokers and nonsmokers. Nicotine Tob Res 2015;17(10):1195-1202. doi: https://doi.org/10.1093/ntr/ntu213. PubMed PMID: 25381306.

4. Patel D, Davis KC, Cox S, et al. Reasons for current E-cigarette use among U. S. adults. Prev Med. 2016;93:14-20. doi: https://doi.org/10.1016/j.ypmed.2 016.09.011. PubMed PMID: 27612572; PMCID: PMC5316292.

5. Rutten LJ, Blake KD, Agunwamba AA, et al. Use of e-cigarettes among current smokers: associations among reasons for use, quit intentions, and current tobacco use. Nicotine Tob Res. 2015;17(10):1228-1234. doi: https:// doi.org/10.1093/ntr/ntv003. PubMed PMID: 25589678; PMCID: PMC4592339.

6. Zhu SH, Zhuang YL, Wong S, Cummins SE, Tedeschi GJ. E-cigarette use and associated changes in population smoking cessation: evidence from US current population surveys. BMJ. 2017;358:j3262. doi: https://doi.org/1 0.1136/bmj.j3262. PubMed PMID: 28747333; PMCID: PMC5526046.

7. Biener $L$, Hargraves JL. A longitudinal study of electronic cigarette use among a population-based sample of adult smokers: Association with smoking cessation and motivation to quit. Nicotine Tob Res. 2015;17(2):127133. doi: https://doi.org/10.1093/ntr/ntu200. PubMed PMID: 25301815; PMCID: PMC4375383.

8. Weaver SR, Huang J, Pechacek TF, Heath JW, Ashley DL, Eriksen MP. Are electronic nicotine delivery systems helping cigarette smokers quit? Evidence from a prospective cohort study of U.S. adult smokers, 2015-2016. PLoS One. 2018;13(7):e0198047. doi: https://doi.org/10.1371/journal.pone.01 98047. PubMed PMID: 29985948; PMCID: PMC6037369.

9. Mirbolouk M, Charkhchi P, Kianoush S, et al. Prevalence and distribution of e-cigarette use among U.S. adults: behavioral risk factor surveillance system, 2016. Ann Intern Med 2018;169(7):429-438. doi: https://doi.org/10.7326/M1 7-3440. PubMed PMID: 30167658

10. Pasquereau A, Guignard R, Andler R, Nguyen-Thanh V. Electronic cigarettes, quit attempts and smoking cessation: a 6-month follow-up. Addiction 2017; 112(9):1620-1628. doi: https://doi.org/10.1111/add.13869. PubMed PMID: 28504457.

11. Al-Delaimy WK, Myers MG, Leas EC, Strong DR, Hofstetter CR. E-cigarette use in the past and quitting behavior in the future: a population-based study. Am J Public Health. 2015;105(6):1213-1219. doi: https://doi.org/10.2105/ AJPH.2014.302482. PubMed PMID: 25880947; PMCID: PMC4431097.

12. Grana RA, Popova L, Ling PM. A longitudinal analysis of electronic cigarette use and smoking cessation. JAMA Intern Med. 2014;174(5):812-813. doi: https://doi.org/10.1001/jamainternmed.2014.187. PubMed PMID: 24664434; PMCID: PMC4122246. 
13. Kalkhoran S, Glantz SA. E-cigarettes and smoking cessation in real-world and clinical settings: a systematic review and meta-analysis. Lancet Respir Med. 2016;4(2):116-128. doi: https://doi.org/10.1016/S2213-2600(15)00521-4. PubMed PMID: 26776875; PMCID: PMC4752870.

14. Manzoli L, Flacco ME, Fiore M, et al. Electronic cigarettes efficacy and safety at 12 months: Cohort study. PLoS One. 2015;10(6):e0129443. doi: https://doi.org/1 0.1371/journal.pone.0129443. PubMed PMID: 26061661; PMCID: PMC4464650.

15. Brose LS, Hitchman SC, Brown J, West R, McNeill A. Is the use of electronic cigarettes while smoking associated with smoking cessation attempts, cessation and reduced cigarette consumption? A survey with a 1-year follow-up. Addiction. 2015;110(7):1160-1168. doi: https://doi.org/10.1111/ add.12917. PubMed PMID: 25900312; PMCID: PMC4862028.

16. Berg CJ, Barr DB, Stratton E, Escoffery C, Kegler M. Attitudes toward ecigarettes, reasons for initiating e-cigarette use, and changes in smoking behavior after initiation: A pilot longitudinal study of regular cigarette smokers. Open J Prev Med. 2014;4(10):789-800. doi: https://doi.org/10.4236/ ojpm.2014.410089. PubMed PMID: 25621193; PMCID: PMC4304080.

17. Shahab L, Goniewicz ML, Blount BC, et al. Nicotine, carcinogen, and toxin exposure in long-term e-cigarette and nicotine replacement therapy users: A cross-sectional study. Ann Intern Med. 2017;166(6):390-400. doi: https:// doi.org/10.7326/M16-1107. PubMed PMID: 28166548; PMCID: PMC5362067.

18. Fagan $P$, Pokhrel $P$, Herzog TA, et al. Sugar and aldehyde content in flavored electronic cigarette liquids. Nicotine Tob Res. 2018;20(8):985-992. doi: https:// doi.org/10.1093/ntr/ntx234. PubMed PMID: 29182761; PMCID: PMC6037055.

19. American Cancer Society. American Cancer Society Position Statement on Electronic Cigarettes. 2018. https://www.cancer.org/healthy/stay-away-fromtobacco/e-cigarette-position-statement.html. Accessed 3 July 2018.

20. Alzahrani T, Pena I, Temesgen N, Glantz SA. Association between electronic cigarette use and myocardial infarction. Am J Prev Med. 2018;55(4):455-461. doi: https://doi.org/10.1016/j.amepre.2018.05.004. PubMed PMID: 30166079; PMCID: PMC6208321.

21. Olfert IM, DeVallance $\mathrm{E}$, Hoskinson $\mathrm{H}$, et al. Chronic exposure to electronic cigarettes results in impaired cardiovascular function in mice. J Appl Physiol (1985). 2018;124(3):573-582. doi: https://doi.org/10.1152/japplphysiol.00713.2 017. PubMed PMID: 29097631; PMCID: PMC5899271.

22. Wagener TL, Floyd EL, Stepanov I, et al. Have combustible cigarettes met their match? The nicotine delivery profiles and harmful constituent exposures of second-generation and third-generation electronic cigarette users. Tob Control. 2017;26(e1):e23-e28. doi: https://doi.org/10.1136/ tobaccocontrol-2016-053041. PubMed PMID: 27729564; PMCID: PMC5574194.

23. Garrett BE, Dube SR, Winder C, Caraballo RS, et al. Cigarette smoking United States, 2006-2008 and 2009-2010. MMWR Suppl 2013;62(3):81-84. PubMed PMID: 24264495.

24. Martell BN, Garrett BE, Caraballo RS. Disparities in adult cigarette smoking United States, 2002-2005 and 2010-2013. MMWR Morb Mortal Wkly Rep. 2016;65(30):753-758. Epub 2016/08/05. doi: https://doi.org/10.15585/mmwr. mm6530a1. PubMed PMID: 27491017.

25. Cobb N, Espey D, King J. Health behaviors and risk factors among American Indians and Alaska Natives, 2000-2010. Am J Public Health. 2014;104 Suppl 3:S481-S489. Epub 2014/04/24. doi: https://doi.org/10.2105/ajph.2014.301 879. PubMed PMID: 24754662; PMCID: PMC4035866.

26. Eichner JE, Cravatt $K$, Beebe LA, et al. Tobacco use among American Indians in Oklahoma: an epidemiologic view. Public Health Rep. 2005;120(2):192199. Epub 2005/04/22. doi: https://doi.org/10.1177/003335490512000214. PubMed PMID: 15842122; PMCID: PMC1497696.

27. Kasza KA, Ambrose BK, Conway KP, et al. Tobacco-product use by adults and youths in the United States in 2013 and 2014. N Engl J Med. 2017; 376(4):342-353. Epub 2017/01/26. doi: https://doi.org/10.1056/NEJMsa16 07538. PubMed PMID: 28121512; PMCID: PMC5317035.

28. Schoenborn CA, Gindi RM. Electronic cigarette use among adults: United States, 2014. NCHS Data Brief 2015(217):1-8. Epub 2015/11/12. PubMed PMID: 26555932

29. Carroll DM, Wagener TL, Thompson DM, et al. Electronic nicotine delivery system use behaviour and loss of autonomy among American Indians: Results from an observational study. BMJ Open. 2017;7(12):e018469. doi: https://doi.org/10.1136/bmjopen-2017-018469. PubMed PMID: 29259060; PMCID: PMC5778282.

30. Comiford AL, Rhoades DA, Spicer $P$, et al. E-cigarettes and tobacco exposure biomarkers among American Indian smokers. Am J Health Behav 2018;42(6): 101-109. doi: https://doi.org/10.5993/AJHB.42.6.10. PubMed PMID: 30158005.
31. Amato MS, Boyle RG, Levy D. How to define e-cigarette prevalence? Finding clues in the use frequency distribution. Tob Control. 2016;25(e1):e24-e29. doi: https://doi.org/10.1136/tobaccocontrol-2015-052236. PubMed PMID: 26085124; PMCID: PMC4683118.

32. Foulds J, Veldheer S, Yingst J, et al. Development of a questionnaire for assessing dependence on electronic cigarettes among a large sample of exsmoking E-cigarette users. Nicotine Tob Res. 2015;17(2):186-192. doi: https:// doi.org/10.1093/ntr/ntu204. PubMed PMID: 25332459; PMCID: PMC4838001.

33. Heatherton TF, Kozlowski LT, Frecker RC, Rickert W, Robinson J. Measuring the heaviness of smoking: using self-reported time to the first cigarette of the day and number of cigarettes smoked per day. Br J Addict 1989;84(7): 791-799. PubMed PMID: 2758152.

34. Flamini G, Romano G, Curigliano G, et al. 4-Aminobiphenyl-DNA adducts in laryngeal tissue and smoking habits: an immunohistochemical study. Carcinogenesis. 1998;19(2):353-357. doi: https://doi.org/https://doi.org/10.1 093/carcin/19.2.353.

35. Shearston J, Lee L, Eazor J, et al. Effects of exposure to direct and secondhand hookah and e-cigarette aerosols on ambient air quality and cardiopulmonary health in adults and children: protocol for a panel study. BMJ Open. 2019;9:e029490. https://doi.org/10.1136/bmjopen-2019-029490.

36. Buu A, Hu YH, Piper ME, Lin HC. The association between e-cigarette use characteristics and combustible cigarette consumption and dependence symptoms: Results from a national longitudinal study. Addict Behav. 2018; 84:69-74. doi: https://doi.org/10.1016/j.addbeh.2018.03.035. PubMed PMID: 29627636; PMCID: PMC5975121.

37. Giovenco DP, Lewis MJ, Delnevo CD. Factors associated with e-cigarette use: a national population survey of current and former smokers. Am J Prev Med. 2014;47(4):476-480. doi: https://doi.org/10.1016/j.amepre.2014.04.009. PubMed PMID: 24880986; PMCID: PMC4214213.

38. Levy DT, Yuan Z, Li Y. The prevalence and characteristics of e-cigarette users in the U.S. Int J Environ Res Public Health. 2017;14(10). doi: https://doi.org/1 0.3390/ijerph14101200. PubMed PMID: 29019917; PMCID: PMC5664701.

39. Morean M, Krishnan-Sarin S, O'Malley SS. Comparing cigarette and ecigarette dependence and predicting frequency of smoking and e-cigarette use in dual-users of cigarettes and e-cigarettes. Addict Behav 2018;87:92-96. doi: https://doi.org/10.1016/j.addbeh.2018.06.027. PubMed PMID: 29975879.

40. Glasser AM, Collins L, Pearson JL, et al. Overview of electronic nicotine delivery systems: A systematic review. Am J Prev Med. 2017;52(2):e33-e66. doi: https://doi.org/10.1016/j.amepre.2016.10.036. PubMed PMID: 27914771; PMCID: PMC5253272.

41. Bhatnagar A, Whitsel LP, Ribisl KM, et al. Electronic cigarettes: a policy statement from the American Heart Association. Circulation. 2014;130(16): 1418-1436. doi: https://doi.org/10.1161/CIR.0000000000000107. PubMed PMID: 25156991

42. Lechner $W$, Meier $E$, Wiener $J$, et al. The comparative efficacy of firstversus second-generation electronic cigarettes in reducing symptoms of nicotine withdrawal. Addiction. 2015;110(5):862-867. doi: https://doi.org/1 0.1111/add.12870. PubMed PMID: 25639148

43. Weaver SR, Kemp CB, Heath JW, Pechacek TF, Eriksen MP. Use of nicotine in electronic nicotine and non-nicotine delivery systems by US adults, 2015. Public Health Rep. 2017;132(5):545-548. doi: https://doi.org/10.1177/0033354 917723597. PubMed PMID: 28880788; PMCID: PMC5593242.

44. Farsalinos KE, Romagna G, Tsiapras D, Kyrzopoulos S, Voudris V. Evaluating nicotine levels selection and patterns of electronic cigarette use in a group of "vapers" who had achieved complete substitution of smoking. Subst Abuse. 2013;7:139-146. doi: https://doi.org/10.4137/SART.S12756. PubMed PMID: 24049448; PMCID: PMC3772898.

45. Etter JF, Eissenberg T. Dependence levels in users of electronic cigarettes, nicotine gums and tobacco cigarettes. Drug Alcohol Depend. 2015;147:6875. doi: https://doi.org/10.1016/j.drugalcdep.2014.12.007. PubMed PMID: 25561385; PMCID: PMC4920051.

46. St Helen G, Dempsey DA, Havel CM, Jacob P, 3rd, Benowitz NL. Impact of eliquid flavors on nicotine intake and pharmacology of e-cigarettes. Drug Alcohol Depend. 2017:178:391-398. doi: https://doi.org/10.1016/j. drugalcdep.2017.05.042. PubMed PMID: 28704768; PMCID: PMC5565733.

47. Kuiper NM, Loomis BR, Falvey KT, et al. Trends in unit sales of flavored and menthol electronic cigarettes in the United States, 2012-2016. Prev Chronic Dis. 2018;15:E105. doi: https://doi.org/10.5888/pcd15.170576. PubMed PMID: 30148426; PMCID: PMC6110400.

48. Shiffman S, Sembower MA, Pillitteri JL, Gerlach KK, Gitchell JG. The impact of flavor descriptors on nonsmoking teens' and adult smokers' interest in 
electronic cigarettes. Nicotine Tob Res 2015;17(10):1255-1262. doi: https:// doi.org/10.1093/ntr/ntu333. PubMed PMID: 25566782.

49. Pearson JL, Richardson A, Niaura RS, Vallone DM, Abrams DB. e-Cigarette awareness, use, and harm perceptions in US adults. Am J Public Health. 2012;102(9):1758-1766. Epub 2012/07/21. doi: https://doi.org/10.2105/ajph.2 011.300526. PubMed PMID: 22813087; PMCID: PMC3474361.

50. Pulvers K, Hayes RB, Scheuermann TS, et al. Tobacco use, quitting behavior, and health characteristics among current electronic cigarette users in a national tri-ethnic adult stable smoker sample. Nicotine Tob Res. 2015;17(9): 1085-1095. Epub 2014/11/12. doi: https://doi.org/10.1093/ntr/ntu241. PubMed PMID: 25385875; PMCID: PMC4627485.

51. Pericot-Valverde I, Gaalema DE, Priest JS, Higgins ST. E-cigarette awareness, perceived harmfulness, and ever use among U.S. adults. Prev Med. 2017;104: 92-99. Epub 2017/07/22. doi: https://doi.org/10.1016/j.ypmed.2017.07.014. PubMed PMID: 28729198; PMCID: PMC5871224.

\section{Publisher's Note}

Springer Nature remains neutral with regard to jurisdictional claims in published maps and institutional affiliations.

Ready to submit your research? Choose BMC and benefit from:

- fast, convenient online submission

- thorough peer review by experienced researchers in your field

- rapid publication on acceptance

- support for research data, including large and complex data types

- gold Open Access which fosters wider collaboration and increased citations

- maximum visibility for your research: over $100 \mathrm{M}$ website views per year

At $\mathrm{BMC}$, research is always in progress.

Learn more biomedcentral.com/submissions 